\title{
Efficacy and cost-effectiveness analysis of steroid in treatment of Otitis Media with Effusion (OME) in children: A Randomized Trial
}

\author{
Anup Acharya ${ }^{1 *}$ iD, Bandana Pokharel ${ }^{2}$, Shiva Bhushan Pandit ${ }^{3}$, Suman Bartaula ${ }^{3}$ \\ 'Department of ENT \& Head and Neck Surgery, Universal College of Medical Sciences, Bhairahawa, Nepal, ${ }^{2}$ College of Nursing, \\ ${ }^{3}$ Department of ENT \& Head and Neck Surgery, Lumbini Medical College, Palpa, Nepal
}

\begin{abstract}
Background: Otitis media with effusion (OME) is a common disorder in children and lacks international consensus for its treatment. Out of various treatment options, few studies have show promising benefits of steroids for this condition. The objective of this study was to find the efficacy of steroid in treatment of OME and compare effectiveness of various modalities of treatment for OME. Also, we conducted their costeffectiveness analysis. Methods: In this experimental study, 160 children between one and 12 years of age having OME between September 2018 and January 2020 were randomized into four parallel groups and were managed with antibiotics-antihistamines-decongestant combination, nasal steroid spray, oral steroid, and watchful observation respectively. They were re-evaluated in one-month period for improvement in OME and appearance of any adverse effects. Improvement was compared with Chi-square test. Results: A total of 160 participants were randomly divided into four groups by block randomization. The group treated with nasal steroid spray showed statistically significant improvement. The group treated with oral steroid showed improvement but was not statistically significant. Improvement was significantly lower in observation group. Cost of treatment was in the decreasing order in antibiotics-combination, nasal steroid spray, oral steroid and observation groups respectively. Conclusions: Topical nasal steroid was the only efficacious treatment among the four modalities for OME. Furthermore, steroids were safe and cheaper than antibiotics combination.
\end{abstract}

Keywords: Antibiotics, antihistamines, children, otitis media with effusion, steroid

\section{Correspondence to:}

Dr. Anup Acharya

Associate Professor, Department of ENT \&

Head and Neck Surgery

Universal College of Medical Sciences

E-mail: anupent@gmail.com

Submitted: $21^{\text {th }}$ July 2020

Accepted: $30^{\text {th }}$ October 2020

To cite: Acharya A, Pokharel B, Pandit SB, Bartaula

S. Efficacy and cost-effectiveness analysis of steroid in treatment of Otitis Media with Effusion (OME) in children: A Randomized Trial. JGMC Nepal. 2020;13(2):111-5.

DOI: 10.3126/jgmcn.v13i2.30198

\section{INTRODUCTION}

Otitis Media with Effusion (OME) is defined as "presence of fluid in the middle ear without signs or symptoms of acute ear infection". ${ }^{1}$ It is a common ear problem in children. Almost all children (90\%) develop this condition before age of five years. Then, they develop it multiple times a year. ${ }^{2}$ As the symptoms are subtle, most of the cases do not seek medical attention until late. Screening of asymptomatic school going children in western part of Nepal revealed the prevalence of OME in 5.6\%. ${ }^{3}$ In the study, $17.3 \%$ of the children had ear wax and hence their status of tympanic membrane could not be evaluated. There is a lack of international consensus in treatment of OME.

Several medical and surgical options are in clinical practice. Medical treatment includes antibiotics, decongestants, antihistaminics, mucolytics, nasal or oral steroids etc. Meta-analysis of most of these modalities showed they lack long-time benefit. ${ }^{4}$ However, some studies have shown promising benefit of steroid, oral and/or nasal, as an option for treatment of OME. ${ }^{5,6}$ Studies 
have also shown that simple observation may be adequate for majority of cases to resolve itself. ${ }^{7}$

There are limited studies on the use of steroids, and to our knowledge there are no studies to compare cost-effectiveness for treatment of OME in our population. We attempted to find if steroid in the form of nasal spray or short-term oral use were efficacious for treatment of OME and compare their effectiveness to that of antibiotics-antihistaminesdecongestants combination and watchful observation. Also, we did their cost-effectiveness analysis.

\section{MATERIALS AND METHODS}

Study type and study design, Place and duration of the study: This was an experimental study conducted in the out-patient clinic of Department of otolaryngology (ENT) of Lumbini Medical College and Teaching Hospital. The study was done from September 2018 till February of 2020. It was registered in the clinical trial registry (https://clinicaltrials. gov/show/NCT03590912).

Sample size calculation: In a study by Cengel et al, ${ }^{6} \mathrm{OME}$ was cured in $14 \%$ of children treated with placebo as compared to $42 \%$ treated with nasal steroid. Assuming same proportion, with alpha error $=5 \%$, power $=80 \%$, minimum sample size in each group is calculated as 39 . We included 40 children in each group. Telephone calls were made in between to reduce loss to follow up.

\section{Sampling method and Inclusion and exclusion criteria:}

All children between one year and 12 years of age during the study period visiting ENT outpatient department (OPD) and diagnosed to have OME were included in the study until participants were enough for the required sample size.

The following children were excluded from the study:

i. Child or parent/guarding not consenting to the study

ii. Cleft palate, down's syndrome or any cranio-facial developmental disorder

iii. History of ear surgery

iv. Systemic disorder like diabetes

v. Treated with steroids in last 6 weeks for any condition

Diagnostic criteria for OME: OME was diagnosed by consultant otolaryngologist based on history, clinical examination and tympanometry. History suggestive of OME included hearing loss, occasional mild ear ache, or deteriorating school performance over last few months. Examination included otoscopy; dull, lusterless, mild retracted tympanic membrane with visible blood vessels in pars tensa adjacent to annulus and absent mobility were features suggestive of OME. Tympanometry was done in children suspected to have OME from history and examination. Diagnosis of OME was made when tympanometry showed B type curve in children suspected to have OME from history and clinical examination. ${ }^{1}$

Diagnostic criteria for improvement: Children with A, As, or $\mathrm{C}$ curve in tympanometry in follow-up examination after a month of initial examination were labelled as improved. Children with B curve were considered to have persistent OME and were labelled as 'not improved'.

Randomization: The children who fulfilled the selection criteria were randomly divided into four parallel groups by block randomization, with blocks of four by a resident not involved in the study. The blocks were generated randomly by an author, who was not directly involved in treatment of patient, according to computer generated random numbers. The groups were as follows:

1. Group A: Antibiotics-antihistamines-nasal decongestant combination

2. Group B: Nasal spray of mometasone furoate

3. Group C: Oral steroid

4. Group D: Watchful observation

Children in Group A were given cefpodoxime at the rate of 10 $\mathrm{mg} / \mathrm{Kg}$ body weight/day in two divided doses for one week, plus levocetirizine for one month at the rate of $1.25 \mathrm{mg}$ once daily for up to six years of age and $2.5 \mathrm{mg}$ for older children, plus oxymetazoline $0.025 \%$ at the rate of four drops in each of both nostrils twice daily for two weeks. Children in Group B were prescribed nasal spray of mometasone furoate 50 microgram/puff for a month. They were instructed to use one puff (50 microgram mometasone) per nostril per day. Parents/guardians and the children were taught on how to use the spray. Children in group $\mathrm{C}$ were prescribed oral prednisolone at the rate of one mg per kg per day in two divided doses for a week followed by $0.5 \mathrm{mg}$ per day for next one week. Parent/guardian and participants of group D were counselled about the condition and its management options and were advised for observation for a month without active treatment. All the participants were advised for follow-up in one-month period. Telephone calls were made every week to reduce the loss of follow-up. Children were re-evaluated with clinical examination including otoscopy and tympanometry during follow-up by consultant otolaryngologist who were not aware whether the children were subjected to study. Children with A, As, or C curve were labelled as improved whereas those with B curve were considered to have persistent OME.

Most commonly used five brands (fewer if not available in market) of a particular molecule in the department in the last three months were listed. Mean cost of those brands for 
each molecule for a course of treatment as described above was calculated in Nepalese Rupees (NRs). This mean cost was used for cost-effectiveness analysis.

Ethical approval and patient consent: It was approved by the Institutional Review Committee of the Hospital. Informed written consent was taken from the accompanying parent or guardian of each child. Verbal consent was taken from the children as appropriate.

Data were collected as per pre-formed proforma. Examination and tympanometry was done on first visit and after one month. The data were entered in Microsoft Excel ${ }^{\text {TM }} 2008$ and imported to SPSS ${ }^{\text {тм }} 16$ (Statistical Package for Social Sciences) for analysis. All the paper proforma were preserved for any future reference. Descriptive statistics were presented as mean, standard deviation (SD), frequency and percentages. Categorical data were analyzed with chi-square test. $P$ value less than 0.05 was considered statistically significant.

\section{RESULTS}

There were a total of 160 participants in the study divided equally into four groups, thus each group consisting of 40 children. Age and gender of the participants is shown in Table 1. Their overall mean age was 6.84 years $(S D=2.97)$. Mean age of participants in the four study-group was comparable $(\mathrm{p}=0.21)$. Of all, 74 (46.25\%) were male and $86(53.75 \%)$ were female and this difference was not significant $\left(X^{2}=0.9\right.$, $\mathrm{p}=0.34$ ). Similarly gender distribution was also comparable between the groups $(\mathrm{p}=0.074)$.

Table 1: Age and Gender of the participants

\begin{tabular}{|c|c|c|c|c|c|c|}
\hline & & \multicolumn{4}{|c|}{ Treatment Groups } & \multirow[t]{2}{*}{ Statistics } \\
\hline & & A & B & C & D & \\
\hline $\begin{array}{l}\text { Age } \\
\text { (mean in years) }\end{array}$ & & 6.98 & 6 & 7.3 & 7.1 & $\begin{array}{l}F=1.53, d f=3, \\
p=.21\end{array}$ \\
\hline \multirow[b]{2}{*}{ Gender (n, \%) } & M & $21(53.5 \%)$ & $14(35 \%)$ & $15(37.5 \%)$ & $24(60 \%)$ & $X^{2}=6.9, d f=3$ \\
\hline & $\mathrm{F}$ & $19(47.5 \%)$ & $26(65 \%)$ & $25(62.5 \%)$ & $16(40 \%)$ & $p=0.074$ \\
\hline
\end{tabular}

Improvement of the OME status in various study groups is presented in Table 2. It shows that the greatest improvement was in group B followed by group $C$ and the least improvement was in group D. Further analysis with Bonferroni correction revealed that the rate of improvement in group B was significantly higher but was not so in group C. Similarly, rate of improvement was significantly lower in control group (group D).

Mean cost of treatment in each group is presented in Table 3. It shows that the cost was highest in group A followed by group B, C and D respectively. Further ad-hoc analysis by
Table 2: Improvement in OME status in various study groups

\begin{tabular}{cccc}
\hline Group & \multicolumn{2}{c}{ Improvement } & Statistics \\
& No & Yes & \\
A & $27(67.5 \%)$ & $13(32.5 \%)$ & $X^{2}=26.6$ \\
B & $13(32.5 \%)^{*}$ & $27(67.5 \%)^{*}$ & $\mathrm{df}=3$ \\
C & $16(40 \%)$ & $24(60 \%)$ & $\mathrm{P}<0.001$ \\
D & $33(82.5)^{*}$ & $7(17.5 \%)^{*}$ & \\
\hline
\end{tabular}

* = statistically significant

Tukey method was done between each pair of groups which showed all the comparisons were statistically significant ( $p$ value $<0.001$ in each of all comparisons).

Table 3: Mean cost of treatment in each group in NRs

\begin{tabular}{ccc}
\hline Group & $\begin{array}{c}\text { Cost } \\
\text { (mean, SD) }\end{array}$ & Statistics \\
A & $681(\mathrm{SD}=75.92)$ & $\mathrm{F}=1405.58$ \\
B & $400(\mathrm{SD}=0)$ & $\mathrm{P}<0.001$ \\
C & $225(\mathrm{SD}=60.38)$ & \\
D & 0 & \\
\hline
\end{tabular}

Adverse effect of medication was reported from two (5\%) cases in group A. Both were minor itching which resolved on its own without additional medical attention. One case $(2.5 \%)$ from group B reported blood tinged nasal discharge which was managed with nasal ointment and counselling regarding proper way of using nasal spray. No adverse effect was reported from group $\mathrm{C}$.

\section{DISCUSSION}

We conducted this study to know the efficacy of steroids, oral and topical nasal, in treatment of OME in children of agegroup two to 12 years, their effectiveness, cost-effectiveness analysis and adverse effect as compared to those of other modalities. We found that nasal steroid spray was the only efficacious treatment of OME among the four modalitis.

There are many meta-analysis and national guidelines about management of OME, however, treatment of this condition is still difficult and vary widely. ${ }^{4,8}$ There is no universal consensus on the management of this condition and an effort to find the best practice management is still going on.

Steroids were useful in resolving OME with greater efficacy in our study. Nasal steroid spray for a month was able to resolve OME in exactly two-thirds of the cases whereas oral steroids in tapering dose for a total duration of two week was able to resolve in $60 \%$ of the cases. The improvement with nasal spray was statistically significant but that with oral steroid was just short of significant. Oral antibiotics with oral anti-histaminics and nasal decongestant drops together were able to improve the cases in only one-third of the cases. In placebo group, there was improvement in less than one- 
fifth of the cases and was statistically less as compared to other groups.

A study from Saudi Arabia found that oral steroid for a week and a combination of oral antibiotics for a week followed by nasal steroid spray for three months found remarkable improvement in OME of one or both ears in children as compared to watchful observation in 6 weeks and three months period. However, in six months and nine months period, the improvement was similar to that of watchful observation. They concluded that oral steroid was useful in resolving OME for a short-term period only and nasal steroid spray did not have a role in improvement. ${ }^{5}$ These findings are somewhat comparable to that of our study. We found remarkable improvement with steroid when evaluated at one-month duration. There was improvement with oral as well as local nasal steroid though improvement with oral was just short of statistical significance. Another study from Egypt studied the role of oral steroid (three weeks) versus nasal steroid spray versus normal saline nasal spray as placebo for 3 months for treatment of OME in children aged six to 14 years of age and found that improvement with oral steroid or nasal steroid spray was statistically significant as compared to that with normal saline placebo. There was no difference in efficacy between oral steroid and topical nasal spray. ${ }^{6}$ This study also support our finding that steroid, oral or nasal, has a role in treatment of OME.

A study from India showed significant improvement of OME with topical nasal steroid, used for six months, in children 2-12 years of age as compared to that of normal saline placebo. This study also revealed improvement in 38\% of OME cases with initial three months of observation. ${ }^{9}$ The findings support our study in terms that the nasal steroid spray significantly improves OME. However, we had a poor improvement (17.5\%) with one month of observation. If we had observed for three months, our improvement rate might have gone up.

Clinical Practice Guidelines published by American Academy of Otolaryngology-Head and Neck Surgery Foundation in 2016 had recommended for watchful observation for three months for children with OME not at risk. ${ }^{1}$ Similarly, it had recommended against using steroid, oral or intranasal, antibiotics, anti-histamines and decongestants. This guidelines partially supports our study in that antibiotics, anti-histamines and nasal decongestants do not improve OME. Their recommendation against steroids was, however, just opposite to our findings showing their efficacy in resolving OME. Improvement with observation was significantly less as compared to other modalities of treatment. This may be because we observed for only one month whereas they had done so for three months.

A Cochrane review in 2016 for the role of antibiotics for treatment of OME revealed that oral antibiotics was helpful in complete resolution of OME at various point of time. ${ }^{10}$ In contrast, our study found that antibiotics along with antihistamines and nasal decongestant drops was able to resolve OME only in $17.5 \%$ cases. Antihistamines and nasal decongestants were not effective in treatment in OME according to a study published in $2014 .{ }^{11}$ We had combined antihistamines with nasal decongestant and antibiotics and found similar results. A study published in 2017 concluded that there was no medical treatment for OME with proven benefit. They recommended observation for three months and if there was no improvement, proceed for surgical management. ${ }^{12}$

There have been studies on other invasive or minimally invasive techniques for treatment of OME. Although the role of oral or intra-nasal steroid has been a matter of debate with only some studies showing benefit, intratympanic steroid has also been found to be effective in resolving OME and preventing its recurrence over the period of six months. ${ }^{13}$ Tympanostomy tube insertion for children with OME and hearing difficulty, and adjuvant adenoidectomy for children over four years of age with nasal obstruction has been recommended by an International convention conference in 2017. ${ }^{4}$ A short-term improvement has been shown by tympanostomy tube placement. However, it has been found useful in prevention of OME in children having recurrent acute otitis media. ${ }^{14}$

Cost-wise, combination of antibiotics, antihistamines and topical nasal decongestants was the costliest regimen followed by topical nasal steroid and oral steroid. There was zero cost for watchful observation. Antibiotics combination, the costliest of the regimen, was not able to effectively resolve OME whereas topical nasal steroids was the most effective management in resolving OME and was cheaper compared to antibiotics combination. Topical nasal steroid was however costlier than oral steroid but was also more effective than the later. A study published in 2010 which claims itself as first economic evaluation of topical nasal steroid for treatment of OME found that the nasal steroid was not cost-effective as compared to normal saline spray placebo. ${ }^{15}$

\section{LIMITATION OF STUDY}

First, we studied a short-term outcome of treatment of OME. It is a condition which resolves itself in certain population over months. In other population it must be treated for months or may need surgical treatment if not resolved with maximum medical management. Our study would have been 
more meaningful if we could have followed-up the cases for a longer duration to see the long-term effectiveness of the modalities of treatment. Second, there might be several factors that may play a role in etiology and improvement of the condition which we did not study in this research.

\section{RECOMMENDATION}

Though several studies have recommended against use of steroids for management of OME, we found that the topical nasal steroid was efficacious in resolution over a short duration. They should be considered as the initial treatment option after a period of observation. Further, more studies are needed to study the benefit of these modalities of treatment over short- and long-term efficacy.

\section{CONCLUSION}

Topical nasal steroid was the only efficacious treatment modality for OME with statistical significance when compared to oral steroid, antibioitics, antihistamines, and nasal topical decongestant combination, and watchful observation. Furthermore, it was safe and cheaper than antibiotics combination but costlier than oral steroids and watchful observation.

\section{REFERENCES}

1. Rosenfeld RM, Shin JJ, Schwartz SR, Coggins R, Gagnon L, Hackell JM, et al. Clinical Practice Guideline: Otitis Media with Effusion (Update). Otolaryngol-Head Neck Surg Off J Am Acad Otolaryngol-Head Neck Surg. 2016 Feb;154(1 Suppl):S1-41. DOI: 10.1177/0194599815623467 PMID: 26832942.

2. Mandel EM, Doyle WJ, Winther B, Alper CM. The incidence, prevalence and burden of $\mathrm{OM}$ in unselected children aged 1-8 years followed by weekly otoscopy through the "common cold" season. Int J Pediatr Otorhinolaryngol. 2008 Apr;72(4):491-9. DOI: 10.1016/j.ijporl.2007.12.008 PMID:18272237.

3. Acharya A, Singh MM, Shrestha A, Pokharel B. Ear Nose Throat (ENT) disorders in Government Schools of FarWestern Nepal. Journal of Lumbini Medical College. 2013 Dec 30;1(2):83-5. DOI: 10.22502/jlmc.v1i2.27

4. Simon F, Haggard M, Rosenfeld RM, Jia H, Peer S, Calmels M-N, et al. International consensus (ICON) on management of otitis media with effusion in children. Eur Ann Otorhinolaryngol Head Neck Dis. 2018 Feb 1;135(1, Supplement):S33-9. DOI: 10.1016/j. anorl.2017.11.009 PMID: 29398506.

5. Hussein A, Fathy H, Amin SM, Elsisy N. Oral steroids alone or followed by intranasal steroids versus watchful waiting in the management of otitis media with effusion. J Laryngol Otol. 2017 Oct;131(10):907-13.
DOI: 10.1017/S0022215117001700 PMID: 28807086.

6. El-Anwar MW, Nofal AA-F, Khazbak AO, Sayed AEE, Hassan MR, El-Anwar MW, et al. The Efficacy of Nasal Steroids in Treatment of Otitis Media with Effusion: A Comparative Study. Int Arch Otorhinolaryngol. 2015 Dec;19(4):298-301. DOI: 10.1055/s-0035-1548535 PMID: 26491474.

7. Qureishi A, Lee Y, Belfield K, Birchall JP, Daniel M. Update on otitis media - prevention and treatment. Infect Drug Resist. 2014 Jan 10;7:15-24. DOI: 10.2147/ IDR.S39637 PMID: 24453496.

8. Robb PJ, Williamson I. Otitis media with effusion in children: current management. Paediatr Child Health. 2016 Jan 1;26(1):9-14. DOI: 10.1016/j. paed.2015.09.002

9. Bhargava R, Chakravarti A. A double-blind randomized placebo-controlled trial of topical intranasal mometasone furoate nasal spray in children of adenoidal hypertrophy with otitis media with effusion. Am J Otolaryngol. 2014 Nov 1;35(6):766-70. DOI: 10.1016/j.amjoto.2014.06.006 PMID: 25151658.

10. Venekamp RP, Burton MJ, Dongen TM van, Heijden GJ van der, Zon A van, Schilder AG. Antibiotics for otitis media with effusion in children. Cochrane Database Syst Rev. 2016;6. Available from: DOI: 10.1002/14651858. CD009163.pub3

11. Nunez-Batalla F, Jaudenes-Casaubon C, Sequi-Canet JM, Vivanco-Allende A, Zubicaray-Ugarteche J. Diagnosis and Treatment of Otitis Media With Effusion: CODEPEH Recommendations. Acta Otorrinolaringol Engl Ed. 2019 Jan 1;70(1):36-46. DOI: 10.1016/j.otoeng.2017.07.004

12. Bonney AG, Goldman RD. Antihistamines for children with otitis media. Can Fam Physician. 2014 Jan 1;60(1):43-6.

13. Amer HS, El-Anwar MW, Elfeky AE. The Efficacy of Adjuvant Intratympanic Steroid Treatment for Otitis Media with Effusion in Children. Int Arch Otorhinolaryngol. 2016 Jul;20(3):244-7. DOI: 10.1055/ s-0035-1564722 PMID: 27413407.

14. Steele DW, Adam GP, Di M, Halladay CH, Balk EM, Trikalinos TA. Effectiveness of Tympanostomy Tubes for Otitis Media: A Meta-analysis. Pediatrics. 2017;139(6). DOI: 10.1542/peds.2017-0125 PMID: 28562283.

15. Petrou S, Dakin H, Abangma G, Benge S, Williamson I. Cost-Utility Analysis of Topical Intranasal Steroids for Otitis Media with Effusion Based on Evidence from the GNOME Trial. Value Health. 2010 Jul 1;13(5):54351. DOI: 10.1111/j.1524-4733.2010.00711.x PMID: 20345546. 